\title{
An $a b$ initio study of the influence of crystal packing on the host-guest interactions of calix[4]arene crystal structures
}

\author{
Mark I. Ogden, ${ }^{* a}$ Andrew L. Rohl ${ }^{a}$ and Julian D. Gale ${ }^{b}$ \\ a School of Applied Chemistry, Curtin University of Technology, GPO Box U1987, Perth, 6845, \\ Australia. E-mail: mark@crystallization.curtin.edu.au; Fax: +618 9266 2300; Tel: +618 92662483 \\ ${ }^{b}$ Department of Chemistry, Imperial College of Science, Technology and Medicine, South Kensington, \\ London, UK SW7 $2 A Y$
}

\section{Received (in Cambridge, UK) 14th June 2001, Accepted 16th July 2001 \\ First published as an Advance Article on the web 9th August 2001}

We report the first quantum mechanical calculations of $p$ tert-butylcalix[4]arene inclusion complexes in the crystalline state with geometrical aspects demonstrating good agreement with experiment, while comparison of the configurations calculated for an isolated complex and in the crystal, illustrate that crystal packing forces contribute to the observed structure of the host-guest assembly.

The solid-state structures of calix $[n]$ arene host-guest complexes have been studied intensively since the archetypal $p$-tertbutylcalix[4]arene-toluene structure was reported. ${ }^{1}$ The structural and dynamic features of this particular system have been studied using a range of experimental methods revealing a remarkably complex structure. ${ }^{2,3}$ To complement experimental studies of this and other host-guest complexes, we have used $a b$ initio methods, within the framework of density functional theory, to calculate the structures and energetics of calixarene complexes in the crystalline state. Through the use of an appropriate method it has been possible to treat both the periodic crystal structure and gas phase molecular systems at the same level. This allows the influence of crystal packing on the host-guest chemistry of calixarenes to be assessed. To this end, geometry optimisations for p-tert-butylcalix[4]arene 1 with the guests toluene and carbon disulfide have been performed.

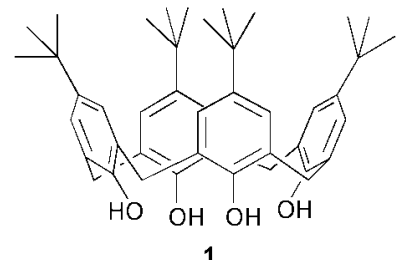

All calculations were performed using the $a b$ initio program SIESTA $^{4}$ which is capable of determining the electronic structure and properties of molecules, surfaces and bulk materials based on density functional theory. For this work, all runs were performed using the non-local density functional of Perdew, Burke and Ernzerhoff.5 The core electrons for all elements were represented by norm-conserving non-local pseudopotentials, while the valence orbitals were described using a double-zeta basis set, with polarisation functions included for non-hydrogens. Here the basis set is a numerical one, consisting of the exact solutions of the pseudopotential for the atomic state, except that a radial confinement is included to localise the orbital corresponding to an energy shift of 0.001 Rydberg. ${ }^{4,6}$ The energy shift used in the present work is smaller than typical values used in many studies. This is necessary to reduce the basis set superposition error (BSSE) that arises due to the radial confinement. Residual BSSE present in binding energies was accounted for using the counterpoise correction. Selected calculations with lower energy shift values verified that the binding configurations are not significantly influenced by further reduction in orbital confinement. A real space mesh equivalent to a planewave cut-off of 150 Rydberg was used for the evaluation of the Hartree and exchange-correlation energies. Optimisations performed on the solid-state structures were constrained at the experimental unit cell dimensions, while all other degrees of freedom were free to relax with no symmetry restrictions.

The results for $p$-tert-butylcalix[4]arene-CS (Fig. 1 and Table 1) show that the guest is less deeply included in the calixarene cavity in the calculated crystal structure as compared to experiment, ${ }^{7}$ although other structural parameters are in reasonable agreement (the two complexes in the calculated unit cell were essentially identical). For comparison, results for the previously reported $a b$ initio RHF/6-31G* calculation ${ }^{8}$ of the gas phase complex are given in Table 1 . In this case, the hostguest intermolecular forces are underestimated to a greater extent, although some parameters, such as the $\mathrm{C}-\mathrm{S}$ bond length are in better agreement with experiment than the present DFT study due to the tendency of the Hartree-Fock calculations to yield shorter bonds. A key finding is that the binding of the guest is weaker in the gas phase $\left(3.2 \mathrm{~kJ} \mathrm{~mol}^{-1}\right)$ than in the solid

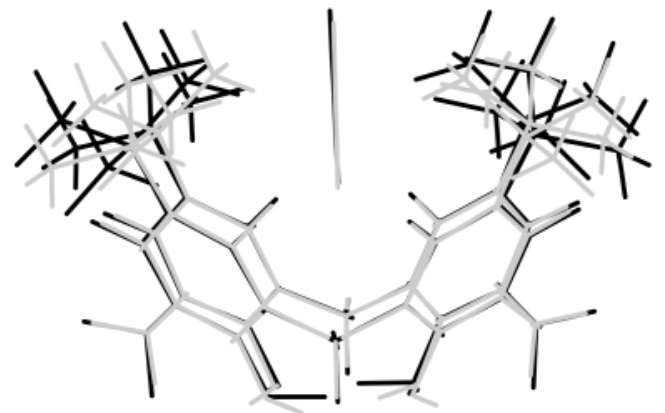

Fig. 1 Superposition of the $p$-tert-butylcalix[4]arene. $\mathrm{CS}_{2}$ structure calculated in the solid-state (in black), and that determined by crystallography (in grey).

Table 1 Comparison between calculated structural parameters in the isolated $p$-tert-butylcalix[4]arene. $\mathrm{CS}_{2}$ assembly and crystal structure, the $\mathrm{RHF} / 6-31 \mathrm{G}^{*}$ calculated structure and the experimental crystal structure (Ar refers to each of the four phenyl rings, and $\mathrm{O}_{4}$ represents the plane defined by the four phenol $\mathrm{O}$ atoms in the calixarene)

\begin{tabular}{lllll}
\hline & $\begin{array}{l}\text { SIESTA- } \\
\text { gas phase }\end{array}$ & $\begin{array}{l}\text { SIESTA- } \\
\text { crystal }\end{array}$ & $\begin{array}{l}\text { RHF/6- } \\
31 \mathrm{G}^{* a}\end{array}$ & $\begin{array}{l}\text { Crystal } \\
\text { structure }^{b}\end{array}$ \\
\hline Ar-O 4 angles $\left(^{\circ}\right)$ & 125.6 & $124.6,124.8$ & 124.7 & 123.5 \\
& 125.6 & $124.7,125.1$ & & \\
& 125.6 & $124.5,124.9$ & & \\
& 125.9 & $124.5,124.4$ & & \\
$\mathrm{C}\left(\mathrm{CS}_{2}\right)-\mathrm{O}_{4}$ & & & & 5.34 \\
distances $(\AA)$ & 5.93 & $5.75,5.80$ & 6.51 & 1.55 \\
$\mathrm{C}-\mathrm{S}$ distance $(\AA)$ & $1.587,1.596$ & $1.583,1.597$ & 1.55 & 0 \\
$\mathrm{O}_{4}-\mathrm{CS}_{2}$ tilt $\left(^{\circ}\right)$ & 1.2 & $0.93,1.24$ & 0 & 0 \\
$a$ Ref. 8. ${ }^{b}$ Ref. 7. & & & & \\
\hline
\end{tabular}


Table 2 Comparison between calculated structural parameters in the isolated $p$-tert-butylcalix[4]arene-toluene assembly and crystal structure, in addition to the experimental crystal structure (Ar refers to each of the four phenyl rings, and $\mathrm{O}_{4}$ represents the plane defined by the four phenol $\mathrm{O}$ atoms in the calixarene)

\begin{tabular}{|c|c|c|c|c|}
\hline & & $\begin{array}{l}\text { SIESTA- } \\
\text { gas phase }\end{array}$ & $\begin{array}{l}\text { SIESTA- } \\
\text { crystal }\end{array}$ & $\begin{array}{l}\text { Crystal } \\
\text { structure }^{a}\end{array}$ \\
\hline $\mathrm{Ar}-\mathrm{O}_{4}$ angles & 1 & 123 & 123,121 & 118 \\
\hline \multirow[t]{3}{*}{$\left({ }^{\circ}\right)$} & 2 & 132 & 127,128 & 126 \\
\hline & 3 & 124 & 122,123 & \\
\hline & 4 & 127 & 126,126 & \\
\hline $\begin{array}{l}\mathrm{CH}_{3}(\mathrm{tol})-\mathrm{O}_{4} \\
\text { distance }(\AA)\end{array}$ & & 3.93 & $3.64,3.66$ & 3.65 \\
\hline Toluene tilt $\left({ }^{\circ}\right)$ & & 3.5 & $1.1,3.8$ & 7 \\
\hline
\end{tabular}

${ }^{a}$ Ref. 2; coordinates obtained from G. D. Enright and J. A. Ripmeester, personal communication.

state $\left(7.7 \mathrm{~kJ} \mathrm{~mol}^{-1}\right)$, consistent with the fact that the cavity in the crystal is defined and influenced by neighbouring calixarene molecules, as well as the main host. However, the absolute binding energies will be underestimated due to the absence of dispersion forces.

Experimental data suggest that the p-tert-butylcalix[4]arene-toluene complex has a $C_{2}$-elliptical calixarene cavity that is dynamically disordered to give an average 4-fold symmetry. ${ }^{2}$ This disorder is associated with rotational disorder of the toluene guest molecule. While inclusion of statistical sampling, typically via dynamical calculations, will be required to study these processes, geometry optimisation gives preliminary results consistent with some aspects of the experimental data. In this case, the two complexes in the calculated crystal structure were slightly different (Table 2). The most striking difference between the calculated structures of the complex in the crystal and the isolated system is the orientation of the guest toluene molecule, along the pseudo 4-fold axis of the host calixarene (Fig. 2). In the isolated assembly, the toluene molecule lies on the pseudo mirror plane intersecting two of the methylene $\mathrm{C}$ atoms (the interplanar angle is $1.5^{\circ}$ ). In the calculated crystal structure, the same interplanar angle is 19.9 and $24.8^{\circ}$, in good agreement with the experimental crystal structure $\left(22.5^{\circ}\right)$. It is likely that the tert-butyl groups of neighbouring calixarenes, which lie 'above' the host calixarene, are inducing this change in orientation. It is also noteworthy that experimental data suggest that the toluene molecule is tilted relative to the calixarene 4 -fold axis by $7^{\circ}$; the calculated results are 1.1 and $3.8^{\circ}$ in the crystal, and $3.5^{\circ}$ in the isolated complex. As observed for the $\mathrm{CS}_{2}$ guest, the toluene is more deeply included in the calculated crystal structure than in the isolated complex (Table 2).

The results presented here clearly demonstrate that crystal packing can have a significant effect on the geometries of hostguest assemblies and that periodic density functional calculations can accurately reproduce this effect. Molecular dynamics calculations will be the next step in studying the disorder observed in the experimental crystal structures.
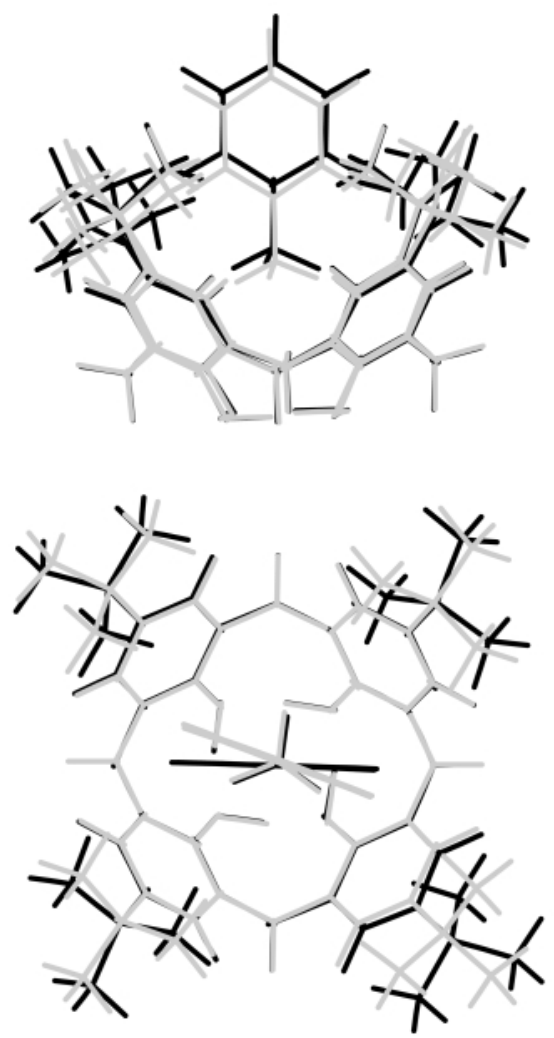

Fig. 2 Side and top views of the superposition of the p-tert-butylcalix[4]arene.toluene structure calculated in the solid-state (in grey), and in the gas phase (in black).

\section{Notes and references}

1 G. D. Andreetti, R. Ungaro and A. Pochini, Chem. Commun., 1979 1005.

2 E. B. Brouwer, G. D. Enright, C. I. Ratcliffe and J. A. Ripmeester, Supramol. Chem., 1996, 7, 79.

3 E. B. Brouwer, J. A. Ripmeester and G. D. Enright, J. Inclusion Phenom Mol. Recognit., 1996, 24, 1; R. Caciuffo, R. Galeazzi, A. J. Horsewill, A Ikram and F. Ugozzoli, Phys. Rev. B, 1999, 60, 11 867; A. Arduini, R. Caciuffo, S. Geremia, C. Ferrero, F. Ugozzoli and F. Zontone, Supramol. Chem., 1998, 10, 125

4 E. Artacho, J. D. Gale, A. Garcia, P. Ordejon and D. Sanchez-Portal, SIESTA Version 1.0.51, 2001; E. Artacho, D. Sanchez-Portal, P. Ordejon, A. Garcia and J. M. Soler, Phys. Stat. Sol. B, 1999, 215, 809; D. Sanchez-Portal, P. Ordejon, E. Artacho and J. M. Soler, Int. J. Quantum Chem., 1997, 65, 453

5 J. P. Perdew, K. Burke and M. Ernzerhof, Phys. Rev. Lett., 1996, 77 3865.

6 O. F. Sankey and D. J. Niklevski, Phys. Rev. B, 1989, 40, 3979.

7 J. Schatz, F. Schildbach, A. Lentz, S. Rastatter, J. Schilling, J. Dormann, A. Ruoff and T. Debaerdemaeker, Z. Naturforsch., Teil B, 2000, 55, 213.

8 J. Schatz, A. C. Backes and H. U. Siehl, J. Chem. Soc., Perkin Trans. 2 , $2000,4,609$. 